\title{
Reactions of Alternate Substrates Demonstrate Stereoelectronic Control of Reactivity in Dialkylglycine Decarboxylase
}

\author{
Shaoxian Sun, Roger F. Zabinski, and Michael D. Toney* \\ Department of Biochemistry, Albert Einstein College of Medicine, 1300 Morris Park Avenue, Bronx, New York 10461
}

Received August 19, 1997; Revised Manuscript Received December 18, 1997

\begin{abstract}
Kinetic and product analyses of the reactions of dialkylglycine decarboxylase with several alternative substrates are presented. Rate constants for the reactions of amino and keto acids of several substrates decrease logarithmically with increasing side-chain size. Conversely, $k_{\text {cat }}$ for L-amino acid decarboxylation increases with side-chain size. These and other data confirm a proposed model for three binding subsites in the active site. In this model, bond making and breaking in both the decarboxylation and transamination half-reactions occurs at the " $A$ " subsite, which maintains the scissile bond aligned with the $\mathrm{p}$ orbitals of the conjugated aldimine and thus maximizes stereoelectronic effects. This strongly supports the proposal by Dunathan (Proc. Natl. Acad. Sci. U.S.A. 55, 712-716) that PLP-dependent enzymes can largely control reaction specificity by specific orientation about $\mathrm{C}^{\alpha}$ in the external aldimine intermediate. The "B" subsite can accept either an alkyl or a carboxylate group, while the "C" subsite accepts only small alkyl groups. This model predicts the existence of nonproductive binding modes for amino acids, which is proposed to be the ultimate origin of the $k_{\text {cat }}$ increase with side-chain size for L-amino acid decarboxylation. The specificity of the 2-aminoisobutyrate decarboxylation half-reaction toward oxidative decarboxylation is very high $\left(<1\right.$ in $10^{5}$ turnovers yields nonoxidative decarboxylation). The origin of this specificity is explored with the reactions of amino- and methylaminomalonate. These substrates exhibit high yields of nonoxidative decarboxylation, providing support for a model in which the interaction between a carboxylate group in the B subsite and Arg406 is a prerequisite to proton donation to and removal from $\mathrm{C}^{\alpha}$.
\end{abstract}

Dialkylglycine decarboxylase (DGD) $)^{1,2}$ from Pseudomonas cepacia is a PLP dependent enzyme that catalyzes the oxidative decarboxylation of 2,2-dialkylglycines, yielding $\mathrm{CO}_{2}$, a ketone, and the PMP form of the enzyme (Scheme $1)$. The catalytic cycle is completed by transamination of an $\alpha$-keto acid, preferentially pyruvate $(1-3)$. The overall reaction catalyzed by DGD is shown below. The unusual

$$
\mathrm{H}_{\mathrm{H}_{3} \mathrm{C}} \mathrm{NO}_{\mathrm{H}_{3} \mathrm{C}}^{\mathrm{O}_{2}{ }^{-}}+\sum_{\mathrm{H}_{3} \mathrm{C}}^{-\mathrm{O}_{2} \mathrm{C}}=0
$$

ability of DGD to catalyze rapidly two classical PLPdependent reactions has rekindled an interest in this enzyme.

The X-ray structure of DGD has been determined to 2.1resolution $(4,5)$. The fold of the enzyme is roughly similar to the well-studied aspartate aminotransferase (6), which is

* Corresponding author: (e-mail) toney@aecom.yu.edu; (tel) 718430-2347; (fax) 718-430-8565.

${ }^{1}$ M.D.T. dedicates this paper to Professor J. F. Kirsch for his patience and wisdom as a teacher. Supported by Grant NIGMS 54779.

${ }^{2}$ Abbreviations: DGD, dialkylglycine decarboxylase; PLP, pyridoxal phosphate; PMP, pyridoxamine phosphate; DGD-PLP, PLP form of DGD; DGD-PMP, PMP form of DGD; AIB, $\alpha$-aminoisobutyrate; AC3C, 1-amino-1-cyclopropanecarboxylate; AC5C, 1-amino-1-cyclopentane-carboxylate; AC6C, 1-amino-1-cyclohexanecarboxylate; $2^{\circ} \mathrm{ADH}$, secondary alcohol dehydrogenase; YADH, yeast alcohol dehydrogenase LDH, lactate dehydrogenase; LADH, liver alcohol dehydrogenase; MAM, $\alpha$-methyl- $\alpha$-aminomalonate; AM, $\alpha$-aminomalonate; TEA-HCl, triethanolamine hydrochloride. a member of evolutionary subgroup I of aminotransferases (7). DGD is a representative member of evolutionary subgroup II (8), and its fold is closely similar to the other known structures of subgroup II enzymes $(9,10)$. The active site structure of DGD is similar to that of aspartate aminotransferase in that the interactions made between coenzyme and protein are highly conserved (5).

Toney et al. (5) proposed a structurally based model of the active site of DGD in which there are three binding subsites $(\mathrm{A}-\mathrm{C})$ that differ in their functional group specificities. One of these subsites, the A subsite, was proposed to be the locus of all bond-making/-breaking events. This model makes predictions about the reaction specificity of various substrate analogues and largely provided the impetus for the present study.

PLP-dependent enzymes catalyze a wide variety of reactions at the $\alpha-, \beta$-, and $\gamma$-carbons of amino acids and amines. Dunathan (11) proposed that reaction specificity in PLP enzymes is largely controlled by specific orientation about the $\mathrm{C}^{\alpha}-\mathrm{N}$ bond in the external aldimine intermediate. Stereoelectronic effects, and thereby reaction rates, are maximized when a bond to $\mathrm{C}^{\alpha}$ is perpendicular to the plane of the PLP ring, i.e., when the bond has maximal overlap with the conjugated $\pi$ system of the aldimine. Direct experimental evidence for this proposal has been sparse. It includes the observations that the $\mathrm{C}^{\alpha}-\mathrm{CH}_{3}$ group of the competitive inhibitor 2-methylaspartate in the active site of aspartate aminotransferase is so oriented (12), that arginine 
Scheme 1: Chemical Mechanism of the DGD-Catalyzed (A) Oxidative Decarboxylation of AIB and (B) Transamination of Pyruvate $^{a}$
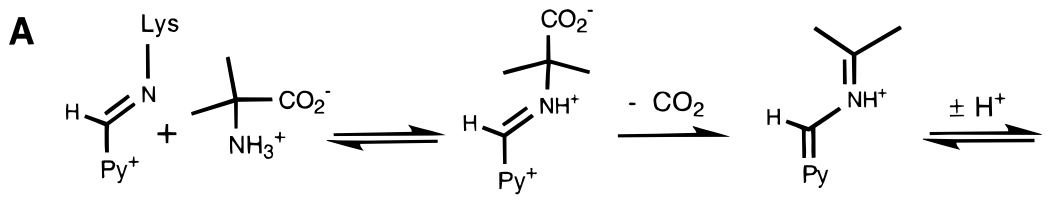

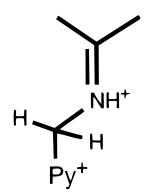

Ketimine

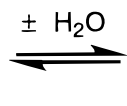

Quinonoid

External Aldimine

$\mathrm{CO}_{2}{ }^{\circ}$

B

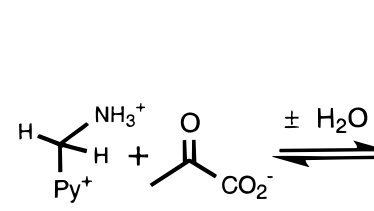

PMP enzyme

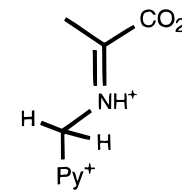

Ketimine
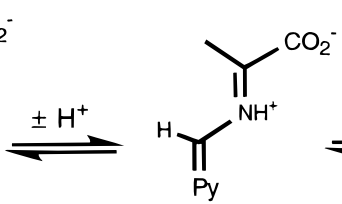

Quinonoid

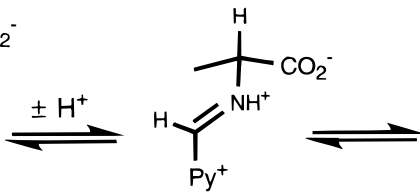

External Aldimine

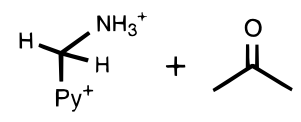

PMP enzyme

${ }^{a}$ The internal aldimine form of the enzyme (in which Lys272 forms a Schiff base with PLP) reacts with amino acids substrates to form the external aldimine intermediate in which the amino acid replaces Lys 272 in the Schiff base with PLP. In the decarboxylation of AIB, CO ${ }_{2}$ loss generates a delocalized carbanion, the quinonoid intermediate, which is specifically protonated on $\mathrm{C}^{\prime}$ to give the ketimine intermediate. This is hydrolyzed to acetone and PMP enzyme. PLP enzyme is regenerated from the PMP form via a classical transamination reaction with pyruvate. PMP enzyme and pyruvate form a ketimine intermediate which is tautomerized to the external aldimine intermediate via a 1,3-prototropic shift encompassing the quinonoid intermediate. The catalytic cycle is completed by transaldimination to regenerate the internal aldimine and yield free L-alanine.

decarboxylase is highly sensitive to the size of the substrate side chain (13), as well as the observed specificity in the tryptophan synthetase-catalyzed $\alpha$-proton exchange of amino acids (14). The variation of reactivity with substrate size for several reactions is presented here and, along with data validating the binding subsite model, provides direct kinetic evidence that, in DGD at least, orientation of a bond to $\mathrm{C}^{\alpha}$ orthogonal to the plane of the pyridine ring greatly activates it toward either transamination or decarboxylation.

The decarboxylation of AIB catalyzed by DGD was known to be specifically oxidative (2), corresponding to protonation of the quinonoid intermediate generated from AIB on the coenzyme $\mathrm{C}^{\prime}$ ' (Scheme 1). This specificity for $\mathrm{C}^{\prime}$ ' protonation in the decarboxylation of AIB is enigmatic since the transamination half-reaction is fully reversible (2), demonstrating that the quinonoid intermediate produced from deprotonation of L-alanine can be reprotonated on either $\mathrm{C}^{\alpha}$ or the coenzyme $\mathrm{C} 4^{\prime}$. Herein, models are proposed to account for this difference in reaction specificity and are discussed in the light of the data presented.

\section{EXPERIMENTAL SECTION}

L-Alanine, D-alanine, and AIB were obtained from Sigma and further purified by recrystallization. PLP, $L-\alpha$-aminobutyric acid, L-norvaline, L-norleucine, D- $\alpha$-aminobutyric acid, D-norvaline, D-norleucine, glycine, isopropylamine, AC3C, AC5C, AC6C, pyruvate, $\alpha$-ketobutyrate, $\alpha$-ketovalerate, $\alpha$-ketoisovalerate, $\alpha$-ketocaproate, NADPH, NADH, and $\mathrm{NAD}^{+}$were purchased from Sigma.

MAM and AM were synthesized according to the procedure of Bailey et al. (15) and stored at $-20{ }^{\circ} \mathrm{C}$. Stock solutions of MAM and AM were neutralized.

Methylaminomalonic Acid. Methylmalonic acid $(7.4 \mathrm{~g}$, $62.5 \mathrm{mmol}$ ) was dissolved in $75 \mathrm{~mL}$ of $2 \mathrm{M} \mathrm{KOH}$. The solution was cooled to $0{ }^{\circ} \mathrm{C}$ and $\mathrm{Br}_{2}(10 \mathrm{~g}, 62.5 \mathrm{mmol})$ was added, which produced an orange solution. The reaction was kept cold and was stirred for $15 \mathrm{~h}$, by which time the color had disappeared. The solution was acidified to below $\mathrm{pH}$ 2.0 and extracted with three $150-\mathrm{mL}$ portions of ethyl acetate.
The solution was reacidified between extractions. The organic fractions were combined, dried over magnesium sulfate, filtered, and concentrated in vacuo to yield a white glassy material $(9.9 \mathrm{~g}, 80 \%)$. The brominated material $(9.6$ g) was dissolved in $150 \mathrm{~mL}$ of concentrated $(30 \%)$ ammonium hydroxide and stirred at $45{ }^{\circ} \mathrm{C}$ for 3 days. This solution was concentrated to yield a white solid. A $1.5 \times$ $27 \mathrm{~cm}$ column of Dowex AG50W-X4 cation-exchange resin was treated with $200 \mathrm{~mL}$ of $1 \mathrm{M} \mathrm{HCl}$ and washed with 400 $\mathrm{mL}$ of distilled water until no residual chloride could be detected with silver nitrate. The white solid was dissolved in $50 \mathrm{~mL}$ of water and eluted with distilled water, and the purest fractions were pooled and concentrated. This material was recrystallized from $80 \%$ methanol to yield white crystals ( $2.6 \mathrm{~g}, 31 \%$ overall) that were $98 \%$ pure by paper chromatography ( $90 \%$ methanol, $R_{f} 0.54$, violet by ninhydrin), $\mathrm{mp}$ 274-276 ${ }^{\circ} \mathrm{C}$. ${ }^{1} \mathrm{H}$ NMR (Bruker $300 \mathrm{MHz}, \mathrm{D}_{2} \mathrm{O}$, TSP at 0 ppm): $1.64\left(\mathrm{CH}_{3}\right) .{ }^{13} \mathrm{C}$ NMR $\left(\mathrm{D}_{2} \mathrm{O}\right.$, TSP at $\left.0 \mathrm{ppm}\right): 22.8$ $\left(\mathrm{CH}_{3}\right), 68.8\left(\mathrm{C}^{\alpha}\right), 176.4\left(2 \times \mathrm{CO}_{2}\right)$. Electrospray ionizationMS: $m / z, 134\left(\mathrm{MH}^{+}\right)$. Approximately $2 \%$ alanine as contaminant was detected by TLC, NMR, electrospray ionization-MS, and enzymatically.

Aminomalonic Acid. Diethylaminomalonate hydrochloride $(6.8 \mathrm{~g}, 32 \mathrm{mmol})$ was dissolved in $80 \mathrm{~mL}$ of $9 \mathrm{M} \mathrm{KOH}$, heated to $60{ }^{\circ} \mathrm{C}$ for $2 \mathrm{~h}$, cooled to room temperature, and stirred for $10 \mathrm{~h}$. AG50W-X4 cation-exchange resin (Bio$\mathrm{Rad}$ ) was washed with $4 \mathrm{M} \mathrm{HCl}$ and then with distilled water until no residual $\mathrm{Cl}^{-}$was detected; portions of this resin were added to the reaction until the $\mathrm{pH}$ was less than 2.3. The $\mathrm{K}^{+}$-containing resin was filtered and the solution was concentrated to a white solid. This material was recrystallized from $20 \mathrm{~mL}$ of water to yield a white powder $(1.1 \mathrm{~g}$, $29 \%$ ) that was pure by paper chromatography (90\% methanol, $R_{f} 0.5$, violet by ninhydrin), $\mathrm{mp} 228-230{ }^{\circ} \mathrm{C} .{ }^{1} \mathrm{H}$ NMR (Bruker $300 \mathrm{MHz}, \mathrm{D}_{2} \mathrm{O}$, TSP at $0 \mathrm{ppm}$ ): $4.16(\mathrm{CH}) .{ }^{13} \mathrm{C}$ NMR $\left(\mathrm{D}_{2} \mathrm{O}\right.$, TSP at $\left.0 \mathrm{ppm}\right): 62.0\left(\mathrm{C}^{\alpha}\right), 173.0\left(2 \times \mathrm{CO}_{2}\right)$. IR $\left(\mathrm{KBr} ; v, \mathrm{~cm}^{-1}\right)$ : $3448\left(\mathrm{NH}_{3}\right) ; 2167,2123\left(2 \times \mathrm{CO}_{2}\right)$. Electrospray ionization-MS: $m / z, 120\left(\mathrm{MH}^{+}\right)$. 
The DGD gene was obtained from Keller et al. (16). An NdeI site was introduced at the initiator methionine codon by PCR. The NdeI/BamHI-digested PCR fragment was inserted into pET-23a, putting DGD expression under the control of the phage T7 promoter. DGD was overexpressed in Escherichia coli strain BL21 (DE3) and purified to nearhomogeneity.

The purification procedure for DGD follows. BL21 (DE3) E. coli cells containing the above expression plasmid were grown in $2 \mathrm{YT}$ at $37^{\circ} \mathrm{C}$ to $A_{600}=0.9$ and induced with 1 mM IPTG. Cells were harvested after $4 \mathrm{~h}$ by centrifugation and resuspended in $20 \mathrm{mM}$ TEA-HCl pH 8.0, $0.1 \mathrm{M} \mathrm{KCl}$, $0.1 \mathrm{mM}$ PLP. They were disrupted by incubation for 30 min with $0.5 \mathrm{mg} / \mathrm{mL}$ lysozyme, followed by sonication. Ammonium sulfate precipitations at $25 \%$ and $35 \%$ were performed. The $35 \%$ pellet was resuspended in $20 \mathrm{mM}$ TEA-HCl pH 8.0, $0.1 \mathrm{mM}$ PLP and chromatographed on a 400-mL Fast Q (Pharmacia) column with a gradient of 20$400 \mathrm{mM} \mathrm{KCl}$ in $20 \mathrm{mM}$ TEA-HCl pH 8.0, $0.1 \mathrm{mM}$ PLP. Fractions were assayed for activity, checked by SDS-PAGE, pooled, and made $1 \mathrm{M}$ in $\mathrm{KCl}$. The protein was loaded onto a 100-mL phenyl Sepharose (Pharmacia) column and eluted with a gradient of $1-0 \mathrm{M} \mathrm{KCl}$. The purest fractions were pooled, aliquoted, flash frozen, and stored at $-80^{\circ} \mathrm{C}$. Protein concentration was determined by the DC protein assay kit from Bio-Rad using BSA as the standard.

$2^{\circ} \mathrm{ADH}, \mathrm{YADH}, \mathrm{LDH}$, glyoxylate reductase, and formaldehyde dehydrogenase were from Sigma. LADH was from Boehringer-Mannheim. Crystals were pelleted by centrifugation and dissolved in $0.1 \mathrm{M}$ potassium phosphate $\mathrm{pH}$ 7.8. Undissolved solid was discarded.

Stopped-Flow Analysis of L-Amino Acid Transamination. An Applied Photophysics SX17.MV stopped-flow apparatus was employed. The reactions were monitored by the spectral changes of the coenzyme. DGD-PLP, $2 \mathrm{mg} / \mathrm{mL}$ in $30 \mathrm{mM}$ TEA-HCl, $0.1 \mathrm{M} \mathrm{KCl}$, was mixed against saturating L-amino acid $\left(K_{\mathrm{M}}\right.$ determined from steady-state decarboxylation reactions) at $25^{\circ} \mathrm{C}$. The reactions exhibited biphasic kinetics and were fitted to two exponentials.

Steady-State Kinetics. AIB decarboxylation was followed by coupling the reaction to that of $2^{\circ} \mathrm{ADH}$, following the decrease in NADPH absorbance that occurs on reduction of acetone to 2-propanol. Pyruvate was used as the $\alpha$-keto acid substrate in all assays unless specified otherwise. AIB was used as the amino acid substrate in assays for $\alpha$-keto acid analogues, which employed $2^{\circ} \mathrm{ADH}$ as the coupling enzyme. Alanine dehydrogenase provides an alternative coupled assay when pyruvate is used as the $\alpha$-keto acid substrate. However, pyruvate is an inhibitor of alanine dehydrogenase, competitive against alanine, limiting the utility of this assay to low pyruvate concentrations. Alanine dehydrogenase was used as the coupling enzyme for the decarboxylation of AC5C and the transamination of isopropylamine, since isopropylamine inhibits $2^{\circ} \mathrm{ADH}$. Possible decarboxylation of $\mathrm{AC} 3 \mathrm{C}$ was checked by coupling to alanine dehydrogenase. Decarboxylations of AC6C and L-phenylglycine were coupled to the LADH reaction $(17,18)$.

Glycine can potentially undergo three reactions with DGD: (1) abstraction of the $\alpha$-proton to form glyoxylate and DGD-PMP via transamination, (2) loss of $\mathrm{CO}_{2}$ with protonation at $\mathrm{C}^{\prime}$ to form formaldehyde and DGD-PMP, (3) loss of $\mathrm{CO}_{2}$ with protonation at $\mathrm{C}^{\alpha}$ to form methylamine and DGD-PLP. These reactions were analyzed by (1) coupling to glyoxylate reductase, (2) coupling to formaldehyde dehydrogenase, and (3) HPLC analysis of amine products (see below). Glycine was incubated with DGD, PLP, and a saturating concentration of pyruvate for $11 \mathrm{~h}$ at $25{ }^{\circ} \mathrm{C}$ (DGD loses no activity over this time), and the products of reaction were quantitated by the assay methods as described above. Control experiments were performed similarly but in the absence of enzyme. All experiments were performed in $30 \mathrm{mM}$ TEA-HCl pH 8.0 with $100 \mu \mathrm{M}$ PLP, $100 \mathrm{mM} \mathrm{KCl}$, and $5 \mathrm{mM} \mathrm{NaCl}$.

The products of oxidative decarboxylation of linear D- and L-amino acids of varying size (i.e., aldehydes of various lengths) were coupled to either YADH or $\mathrm{LADH}$, with saturating pyruvate as the second substrate for the D isomers and the cognate $\alpha$-keto acid as the second substrate for the $\mathrm{L}$ isomers.

The rate of the AIB reaction in the presence of $\mathrm{AC} 3 \mathrm{C}$ was measured at various concentrations of AIB with several fixed concentrations of $\mathrm{AC} 3 \mathrm{C}$. The reaction was coupled to $2^{\circ} \mathrm{ADH}$, with saturating pyruvate. The value of $K_{\mathrm{i}}$ was determined by curve fitting to eq 1 , where $v_{\mathrm{i}}$ is the initial

$$
v_{\mathrm{i}}=\frac{V_{\max }[\mathrm{S}]}{K_{\mathrm{M}}\left(1+[\mathrm{I}] / K_{\mathrm{i}}\right)+[\mathrm{S}]}
$$

rate, $V_{\max }$ the maximal velocity, $K_{\mathrm{M}}$ the Michaelis constant, and $K_{\mathrm{i}}$ the inhibition constant.

$2^{\circ} \mathrm{ADH}$ is inhibited by isopropylamine. Thus, $K_{\mathrm{i}}$ for isopropylamine in the AIB reaction was measured by following the formation of ${ }^{14} \mathrm{CO}_{2}$ from labeled AIB. Reactions were started by addition of DGD to test tubes containing filter paper soaked in Hyamine at the top, above the reaction solutions. The tubes were covered with Parafilm, and at appropriate times, reactions were stopped by acidification with $\mathrm{H}_{2} \mathrm{SO}_{4} . \mathrm{CO}_{2}$ was allowed to collect on the filter paper for $30 \mathrm{~min}$ after acidification. Radioactivity trapped on the filter paper was determined by scintillation counting. The linear phases of plots of ${ }^{14} \mathrm{CO}_{2}$ vs time were used to determine initial rates of decarboxylation.

HPLC Detection of Amine Formation in Nonoxidative Decarboxylation. The reactions of several amino acid substrates were analyzed for the formation of the corresponding amines through nonoxidative decarboxylation. Reactions $(1 \mathrm{~mL})$ contained $10 \mathrm{mM}$ amino acids, $2 \mathrm{mM}$ $\alpha$-keto acid, $0.1 \mathrm{mM}$ PLP, $0.1 \mathrm{M} \mathrm{KCl}, 2-20 \mu \mathrm{M} \mathrm{DGD}$, and $20 \mathrm{mM}$ TEA-HCl pH 8.0 and were run for $2-10 \mathrm{~h}$ at 25 ${ }^{\circ} \mathrm{C}$. They were terminated by addition of $2 \mu \mathrm{L}$ of $98 \% \mathrm{H}_{2}-$ $\mathrm{SO}_{4}$. The quenched solutions were filtered through Centricon-30 concentrators (Amicon) to remove DGD. Filtrates were derivatized by an $o$-phthaldialdehyde (OPA) reagent, and the derivatives were analyzed by $\mathrm{C} 18$ reversed-phase HPLC (19). (Conditions: solvent A, 30\% methanol, 0.05 $\mathrm{mM} \mathrm{K}_{2} \mathrm{HPO}_{4}$, $\mathrm{pH} 6.0$; solvent $\mathrm{B}, 80 \%$ methanol; gradient, $0-100 \% \mathrm{~B}$ in $20 \mathrm{~min}$; flow rate, $1 \mathrm{~mL} / \mathrm{min}$; detectors, UV at $340 \mathrm{~nm}$, fluorescence excitation $360 \mathrm{~nm}$, emission 455 $\mathrm{nm}$.) Control experiments were performed in the absence of DGD under otherwise identical conditions. Derivatized amino acids and amines were quantitated with a calibration curve from standard solutions. Ser or Glu was employed as the internal standard. 
Table 1: Decarboxylation and Transamination of Amino Acid Substrates ${ }^{a}$

\begin{tabular}{|c|c|c|c|c|c|}
\hline & \multicolumn{2}{|c|}{ decarboxylation } & \multirow{2}{*}{$\begin{array}{c}\text { nonoxidative } \\
\text { decarboxylation }(\%)\end{array}$} & \multicolumn{2}{|c|}{ transamination } \\
\hline & $k_{\text {cat }}\left(\mathrm{s}^{-1}\right)$ & $k_{\mathrm{cat}} / K_{\mathrm{M}}\left(\mathrm{M}^{-1} \mathrm{~s}^{-1}\right)$ & & $k_{\text {cat }}\left(\mathrm{s}^{-1}\right)$ & $k_{\text {cat }} / K_{\mathrm{M}}\left(\mathrm{M}^{-1} \mathrm{~s}^{-1}\right)$ \\
\hline AIB & $25^{b}(1)$ & $7.2(0.5) \times 10^{3}$ & $<0.001$ & na & na \\
\hline $\mathrm{AC}^{2} \mathrm{C}^{c}$ & $0.98(0.03)$ & $2.2(0.2) \times 10^{2}$ & $<0.01$ & na & na \\
\hline AC6C & $2.3(0.2)$ & $43(3)$ & $<0.01$ & na & na \\
\hline L-Ala & $3.3(0.3) \times 10^{-2}$ & $4.7(0.7)$ & $9.8(3.0)$ & $21^{b}(2)$ & $3.5(0.6) \times 10^{3}$ \\
\hline D-Ala & $0.20(0.02)$ & $28(5)$ & $3.7(0.2)$ & $<10^{-5 d}$ & nd \\
\hline L-phenylglycine ${ }^{e}$ & $0.20(0.03)$ & $24(5)$ & $5.8(0.8)$ & nd & nd \\
\hline glycine $^{f}$ & $1.2(0.1) \times 10^{-4}$ & $5.2(0.9) \times 10^{-4}$ & $<1.5$ & $2.5(0.3) \times 10^{-4}$ & $1.1(0.2) \times 10^{-3}$ \\
\hline isopropylamine & na & na & na & $7.2(0.5) \times 10^{-3}$ & $7.7(1.0) \times 10^{-2}$ \\
\hline
\end{tabular}

${ }^{a}$ Conditions: $30 \mathrm{mM}$ TEA-HCl, $\mathrm{pH} 8.0,0.02-16 \mu \mathrm{M}$ DGD, $100 \mu \mathrm{M}$ PLP, $100 \mathrm{mM} \mathrm{KCl}, 5 \mathrm{mM} \mathrm{NaCl}, 0.1-2 \mathrm{mM}$ pyruvate, $25^{\circ} \mathrm{C}$. The values reported here have been corrected for the presence of $40 \%$ slowly reacting enzyme whose contribution can be neglected. na, not applicable; nd, not determined. As described in the Experimental Section, various assays were used to determine the kinetic parameters. Errors are given in parentheses.

${ }^{b}$ The values of $k_{\text {cat }}$ reported for the decarboxylation of AIB and the transamination of L-Ala are $k_{\max }$ values measured directly in stopped-flow experiments. The value for AIB was taken from ref 3 . The value of $k_{\max }$ for the reaction of DGD-PMP with pyruvate is calculated to be $\geq 43 \mathrm{~s}^{-1}$ (Table 2), and thus, the $k_{\text {cat }}$ values reported for the other substrates are very nearly equal to $k_{\max }$ for the corresponding half-reactions. ${ }^{c} \mathrm{AC} 3 \mathrm{C}$ did not give a detectable decarboxylation reaction. It is a competitive inhibitor against AIB. $K_{\mathrm{i}}=1.4 \pm 0.2 \mathrm{mM}$ in the presence of saturating pyruvate in the $2^{\circ} \mathrm{ADH}$ coupled assay. ${ }^{d}$ Estimated from the results of Bailey et al. (15). ${ }^{e}$ The D isomer of phenylglycine showed no detectable reaction. The calculated limit on $k_{\text {cat }} / K_{\mathrm{M}}$ is $0.2 \mathrm{M}^{-1} \mathrm{~s}^{-1} .{ }^{f}$ Glycine is a competitive inhibitor against AIB with an inhibition constant $K_{\mathrm{i}}=0.23 \pm 0.03 \mathrm{M}$. Assuming $\mathrm{CO}_{2}$ loss in glycine decarboxylation is rate-limiting, the value of $K_{\mathrm{i}}$ is taken as that for $K_{\mathrm{M}}$.

Decarboxylation of MAM and AM. MAM can potentially undergo both oxidative and nonoxidative decarboxylation. These reactions form pyruvate and alanine, respectively. $\alpha$-Ketobutyrate, yielding $\alpha$-aminobutyrate on reaction with DGD-PMP generated in oxidative decarboxylation, was used as the $\alpha$-keto acid substrate for the determination of the oxidative to nonoxidative decarboxylation ratio. This ratio was determined by HPLC quantitation of the alanine and $\alpha$-aminobutyrate formed. The initial rate of decarboxylation was measured by coupling the reaction to alanine dehydrogenase in the presence of $20 \mu \mathrm{M}$ pyruvate (the half-reaction of MAM decarboxylation is rate limiting under such condition). The rate of nonenzymatic reaction of MAM is subtracted from the overall rate of the enzymatic reaction as a background.

Pyruvate was used as the $\alpha$-keto acid substrate with AM since glycine is formed in nonoxidative decarboxylation. Reactions were quenched and analyzed by HPLC as described above. The ratio of oxidative to nonoxidative decarboxylation was determined by quantitation of glycine and alanine.

\section{RESULTS}

Oxidative Decarboxylation of Amino Acid Substrates. The kinetic parameters for the reactions of several amino acid substrates examined are given in Table 1 . The value of $k_{\text {cat }} /$ $K_{\mathrm{M}}$ for a ping-pong kinetic mechanism measured in steadystate kinetics is the same as the value of $k_{\max } / K_{\text {app }}$ obtained by pre-steady-state analyses (20). Thus, the decarboxylation half-reaction is quite sensitive to changes in substrate structure, as seen by the large variation in $k_{\mathrm{cat}} / K_{\mathrm{M}}$ in Table 1.

The value of $k_{\text {cat }}$ for oxidative decarboxylation is also highly dependent on substrate structure. The best substrate examined is AIB. Replacement of either of the $\alpha$-methyl groups of AIB with a hydrogen atom decreases the value of $k_{\text {cat }}$ for decarboxylation by a factor of at least several hundredfold (AIB vs L- and D-Ala). The replacement of both methyl groups of AIB simultaneously with hydrogens (i.e., glycine) leads to a further $\sim 1000$-fold decrease in decarboxylation $k_{\text {cat }}$.
Chart 1: Structures of and Abbreviations for Amino Acid Substrates Employed in the Present Study.<smiles>CC(C)(C)C(=O)O</smiles><smiles>[NH3+]C1(C2([AsH2+])CC2)CC1</smiles>

AC3C

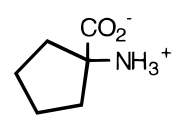

AC5C

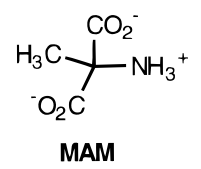<smiles>NC1(C(=O)[O-])CCCCC1</smiles>

AC6C<smiles>NC(=O)C([NH3+])C(=O)O</smiles><smiles>[14CH3]C([NH3+])c1ccccc1</smiles>

Phenylglycine
Three cyclic amino acids (AC3C, AC5C, and AC6C; Chart 1) were examined as decarboxylation substrates. AC $3 \mathrm{C}$ did not give a detectable reaction when incubated with $3 \mu \mathrm{M}$ DGD-PLP for $20 \mathrm{~min}$ using alanine dehydrogenase as coupling enzyme. It binds readily to DGD-PLP, as demonstrated by its competitive inhibition against $\mathrm{AIB}\left(K_{\mathrm{i}}=\right.$ $1.4 \pm 0.2 \mathrm{mM}$ ). Both AC5C and AC6C are intermediate in their reactivities toward oxidative decarboxylation. Their $k_{\text {cat }}$ values are 25-50-fold reduced from that of AIB. The $K_{\mathrm{M}}$ value for AC5C is 12 -fold lower than that for AC6C (4.5 vs $54 \mathrm{mM})$.

L- and D-phenylglycine were tested as substrates. Oxidative decarboxylation was detected only for the $\mathrm{L}$ isomer; 10 $\mathrm{mM}$ D-phenylglycine showed no reaction with $3 \mu \mathrm{M}$ DGDPLP after $20 \mathrm{~min}$. The value of $k_{\text {cat }}$ for the $\mathrm{L}$ isomer is 300 fold lower than for AIB, while $K_{\mathrm{M}}$ is relatively low at 8.2 $\mathrm{mM}$.

Table 2 collects data for the reactions of aminomalonate and 2-methylaminomalonate with DGD-PLP. Both of these $\alpha$-dicarboxylates react $\sim 3000$-fold slower than does AIB.

The dependence of reactivity on the size of the side chain was measured for both D- and L-amino acids. Figure 1 presents data obtained for the oxidative decarboxylation reaction of D-amino acids with one to four side-chain carbons. The logarithms of both $k_{\mathrm{cat}} / K_{\mathrm{M}}$ and $k_{\mathrm{cat}}$ show a linear dependence on the size of the substrate. Figure 2 presents data for the oxidative decarboxylation of L-amino acids. Glycine (zero side-chain carbons) is included in this figure 
Table 2: Decarboxylation of Aminomalonates ${ }^{a}$

\begin{tabular}{llcc}
\hline & \multicolumn{2}{c}{ decarboxylation } & $\begin{array}{c}\text { nonoxidative } \\
\text { decarboxylation }(\%)\end{array}$ \\
\cline { 2 - 4 } & \multicolumn{1}{c}{$k_{\text {cat }}\left(\mathrm{s}^{-1}\right)$} & $k_{\text {cat }} / K_{\mathrm{M}}\left(\mathrm{M}^{-1} \mathrm{~s}^{-1}\right)$ & $56(9)$ \\
MAM & $7.9(0.8) \times 10^{-3}$ & $1.1(0.2)$ & $94(6)$ \\
AM $^{b}$ & $25(6) \times 10^{-3}$ & $0.11(0.03)$ & \\
\hline
\end{tabular}

${ }^{a}$ Conditions: $30 \mathrm{mM}$ TEA-HCl, $\mathrm{pH} 8.0,6-16 \mu \mathrm{M}$ DGD, $100 \mu \mathrm{M}$ PLP, $100 \mathrm{mM} \mathrm{KCl}, 5 \mathrm{mM} \mathrm{NaCl}, 20 \mu \mathrm{M}-2 \mathrm{mM}$ keto acids, $25^{\circ} \mathrm{C}$. The values reported here have been corrected for the presence of $40 \%$ slowly reacting enzyme whose contribution can be neglected. Errors are given in parentheses. ${ }^{b}$ Measured by HPLC as described in the Experimental Section.

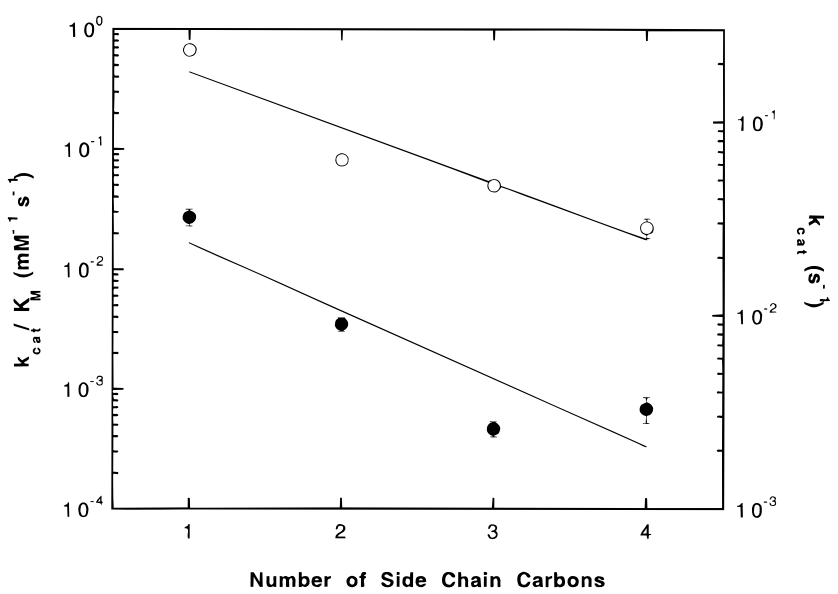

FIGURE 1: Semilog plot of rate constants for the oxidative decarboxylation of D-amino acids with linear side chains of one to four carbons in length. The rate constants were measured in steadystate reactions in which the aldehydes produced from oxidative decarboxylation were coupled to alcohol dehydrogenase. The logarithms of both $k_{\text {cat }} / K_{\mathrm{M}}$ (closed circles) and $k_{\text {cat }}$ (open circles) show a linear dependence on side-chain size. Lines are from linear regression. Error bars are plotted over and partially obscured by the data points.

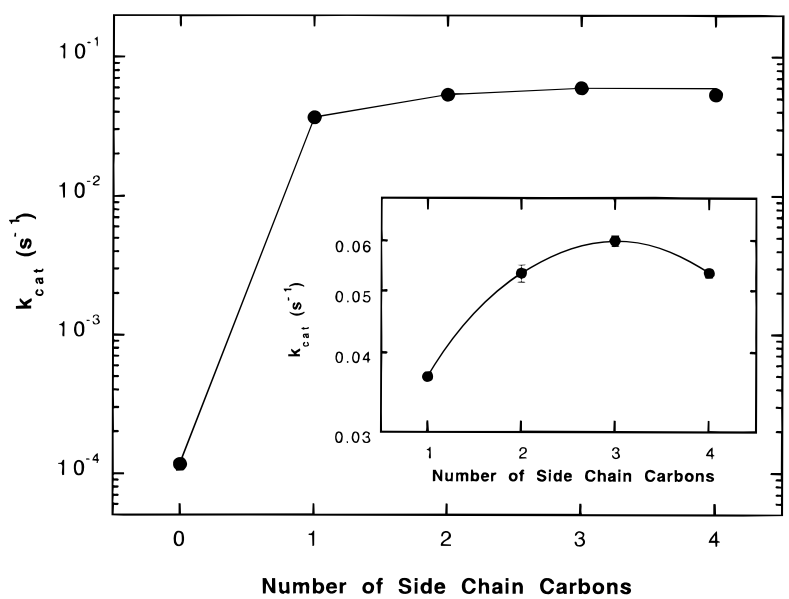

FIGURE 2: Semilog plot of rate constants for the oxidative decarboxylation of L-amino acids with linear side chains of one to four carbons in length. The rate constants were measured in steadystate reactions in which the aldehydes produced from oxidative decarboxylation were coupled to alcohol dehydrogenase, except that for glycine which was coupled to formaldehyde dehydrogenase. The inset highlights the increase in decarboxylation $k_{\text {cat }}$ with increasing side-chain size observed for substrates with $1-4$ sidechain carbons. Lines are drawn simply to guide the eye. Error bars are plotted over and partially obscured by the data points.

to highlight the large effect of an $\alpha$-alkyl group on reactivity. Remarkably, the value of $k_{\max }$ for the decarboxylation of L-amino acids increases with increasing size from one to three side-chain carbons and then begins to decrease at four side-chain carbons.

Percent Nonoxidative Decarboxylation of Amino Acid Substrates. The ratios of oxidative to nonoxidative decarboxylation (Scheme 2) were measured for the reactive amino acids. These are presented as percent nonoxidative decarboxylation for $\alpha$-monocarboxylic and $\alpha$-dicarboxylic substrates in Tables 1 and 2, respectively. Nonoxidative decarboxylation for AIB was not detectable with the procedures used; less than 1 in $10^{5}$ turnovers occurs through the nonoxidative pathway (Scheme 2). The two other $\alpha$-dialkyl substrates examined, AC5C and AC6C, also gave undetectable amounts of the corresponding amine products produced via nonoxidative decarboxylation.

A significant fraction $(\sim 5 \%)$ of the reactions of both isomers of Ala occurs via the nonoxidative pathway. The other substrate with one $\alpha$-hydrogen, L-phenylglycine, shows a similar amount of nonoxidative decarboxylation. The measured oxidative/nonoxidative ratio for glycine is less reliable due to the small amount of glycine reacted.

The aminomalonates (Table 2) both show much larger ratios of nonoxidative to oxidative decarboxylation. Nonoxidative decarboxylation occurs $\sim 50 \%$ and $\sim 95 \%$ of the time with MAM and AM, respectively.

Transamination of Amino Acid Substrates. Of the amino acids, L-Ala is the best transamination substrate examined. The results of Bailey et al. (15) from experiments employing radioisotopes allow one to estimate that the $k_{\text {cat }}$ for D-Ala is, at most, $10^{-6}$ that for L-Ala. For glycine, in which the $\alpha$-methyl group of Ala is replaced with a hydrogen, $k_{\text {cat }}$ is reduced $10^{5}$-fold. The $K_{\mathrm{i}}$ for glycine as a competitive inhibitor against AIB is $230 \pm 30 \mathrm{mM}$. For isopropylamine, in which the $\alpha-\mathrm{CO}_{2}{ }^{-}$of Ala is replaced by a methyl group, $k_{\text {cat }}$ is reduced by a factor of $\sim 10^{4}$. The $K_{\mathrm{M}}$ value for isopropylamine is $94 \pm 10 \mathrm{mM}$, which is in reasonable agreement with $K_{\mathrm{i}}=36 \pm 4 \mathrm{mM}$ determined from competitive inhibition against AIB.

The dependence of $k_{\max }$ (the maximal half-reaction rate constant) for transamination on substrate size is shown in Figure 3. The value of $\log k_{\max }$ for the fast phase observed in the stopped flow (see Sun et al. (38) for a discussion of the origin of the biphasicity) in the transamination of substrates with one to four side-chain carbons decreases linearly with substrate size. As in the decarboxylation of L-amino acids, glycine (zero side-chain carbons) is transaminated very much slower than is L-alanine (one side-chain carbon).

Transamination of $\alpha$-Keto Acid Substrates. Table 3 presents rate constants for the reactions of $\alpha$-keto acids with DGD-PMP in the transamination half-reaction. These data are presented graphically in Figure 4. Glyoxylate is largely hydrated in aqueous solution. The value of $K_{\mathrm{M}}$ was thus corrected by a factor of 260 (21). On the other hand, aldehydes are intrinsically more reactive than ketones toward Schiff base formation by a factor of $\sim 150$ (22). Thus, the $K_{\mathrm{M}}$ value for glyoxylate was also corrected for this effect. The final $K_{\text {app }}$ value for glyoxylate is $0.40 \pm 0.06 \mathrm{mM}$. The calculated $K_{\text {app }}$ values (i.e., $k_{\max } /\left(k_{\text {cat }} / K_{\mathrm{M}}\right)$ ) for the other $\alpha$-keto acids range from 0.5 (pyruvate) to $8 \mathrm{mM}$ ( $\alpha$-ketocaproate).

The value of $\log k_{\text {cat }} / K_{\mathrm{M}}$ is linearly dependent on the $\alpha$-keto acid side-chain size, not including glyoxylate. Similarly, the calculated $k_{\max }$ values are linearly dependent on side-chain 
Scheme 2: Decarboxylation Reaction Scheme Illustrating Divergence at the Quinonoid Intermediate to Either Nonoxidative or Oxidative Decarboxylation ${ }^{a}$

\section{Nonoxidative Decarboxylation}

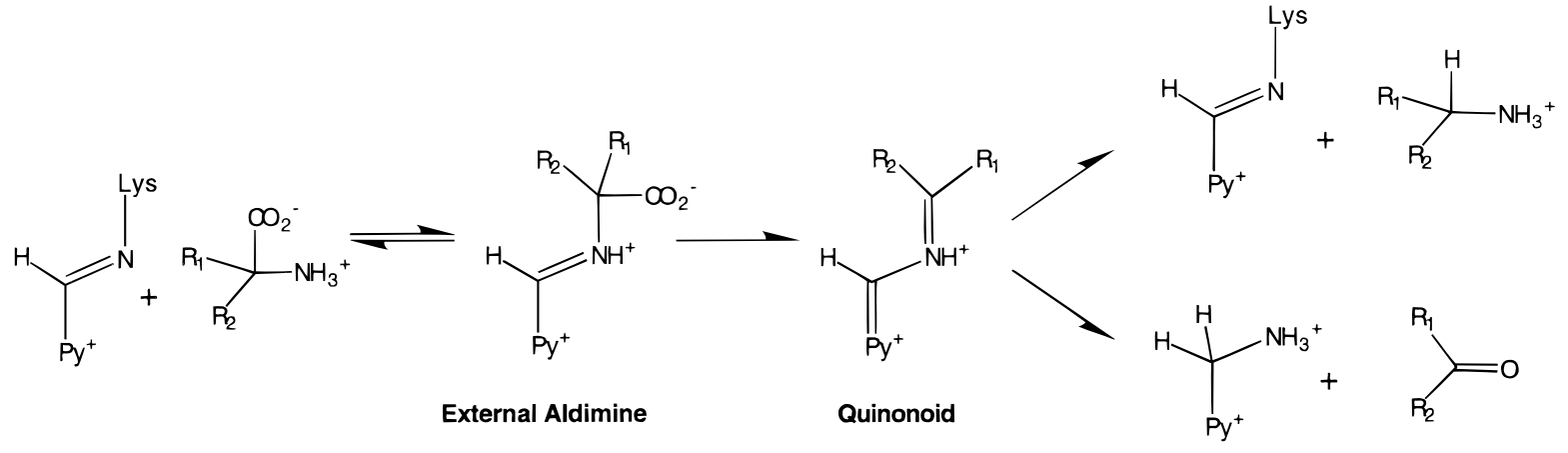

\section{Oxidative Decarboxylation}

${ }^{a}$ Nonoxidative decarboxylation results from protonation of the quinonoid on $\mathrm{C}^{\alpha}$, whereas oxidative decarboxylation results from protonation of the quinonoid on $\mathrm{C}^{\prime}$. Nonoxidative decarboxylation yields a primary or secondary amine while oxidative decarboxylation yields an aldehyde or ketone.

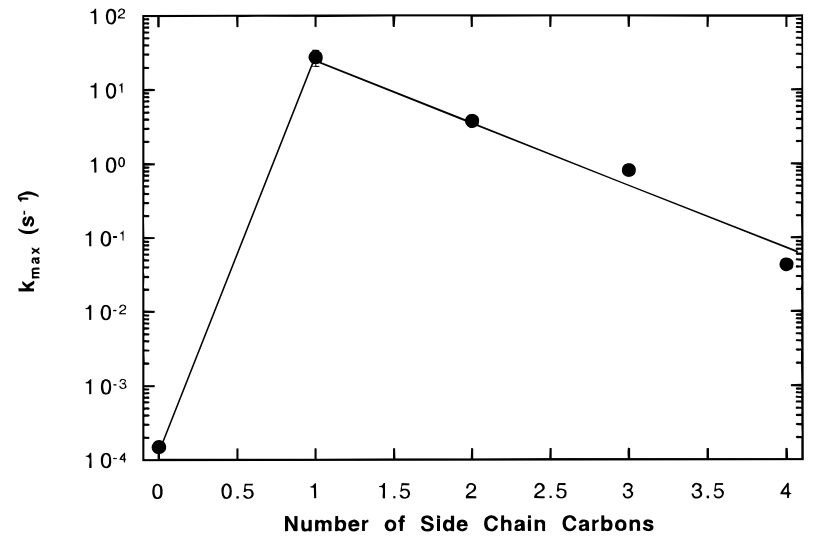

FIGURE 3: Semilog plot of rate constants for the fast phase of the transamination of L-amino acids with linear side chains of one to four carbons in length. Rate constants were obtained from stoppedflow analysis of the transamination half-reactions. The line for zero to one carbon is drawn for the eye, while that for one to four carbons is from linear regression. Error bars are plotted over and partially obscured by the data points.

size only for one to four carbons. Glyoxylate, with zero side-chain carbons, is unusually unreactive, as is glycine in the amino acid series. Whereas the difference in reactivity between substrates with zero and one side-chain carbon in the amino acid series is $\sim 10^{5}$-fold, the difference with $\alpha$-keto acids is only $\sim 100$-fold.

\section{DISCUSSION}

Binding Subsite Specificity. Dunathan (11) proposed that PLP-dependent enzymes can control reaction specificity by specifically orienting one of the bonds to $\mathrm{C}^{\alpha}$ in the external aldimine intermediate so that it is parallel to the $\mathrm{p}$ orbitals of the conjugated $\pi$ system of the aldimine. This is illustrated in Figure 5. The parallel orientation provides maximal $\sigma-\pi$ orbital overlap in the transition state, thereby lowering transition-state energy and maximizing reaction rate. Such stereoelectronic activation is well documented in organic chemistry (23), and evidence for its importance in enzymatic reactions is mounting (24).

Assuming that Dunathan's proposition is essentially correct, one can construct a functional model of the DGD active

\begin{tabular}{|c|c|c|}
\hline substrate $\mathrm{RCOCO}_{2}^{-}$ & $\begin{array}{c}\text { calcd } \\
k_{\max }^{b}\left(\mathrm{~s}^{-1}\right)\end{array}$ & $\begin{array}{c}k_{\text {cat }} / K_{\mathrm{M}} \times 10^{-3} \\
\left(\mathrm{M}^{-1} \mathrm{~s}^{-1}\right)\end{array}$ \\
\hline glyoxylate $^{c} \mathrm{R}=\mathrm{H}$ & $1.6(0.1)$ & 4. \\
\hline pyruvate $\mathrm{R}=\mathrm{CH}_{3}$ & $43(6)$ & 93 \\
\hline$\alpha$-ketobutyrate $\mathrm{R}=\mathrm{CH}_{2} \mathrm{CH}_{3}$ & $29(1)$ & \\
\hline$\alpha$-ketovalerate $\mathrm{R}=\left(\mathrm{CH}_{2}\right)_{2} \mathrm{CH}_{3}$ & $12(1)$ & 5) \\
\hline$\alpha$-ketoisovalerate $\mathrm{R}=\mathrm{CH}\left(\mathrm{CH}_{3}\right)_{2}$ & 6.8 & 0. \\
\hline$\alpha$-ketocaproate $\mathrm{R}=\left(\mathrm{CH}_{2}\right)_{3} \mathrm{CH}_{3}$ & $1.3(0.1)$ & $0.16(0.04)$ \\
\hline \multicolumn{3}{|c|}{$\begin{array}{l}{ }^{a} \text { Conditions: } 30 \mathrm{mM} \text { TEA-HCl, } \mathrm{pH} 8.0,0.02-0.1 \mu \mathrm{M} \text { DGD, } 100 \\
\mu \mathrm{M} \text { PLP, } 100 \mathrm{mM} \mathrm{KCl}, 5 \mathrm{mM} \mathrm{NaCl}, 60 \mathrm{mM} \text { AIB, } 25^{\circ} \mathrm{C} \text {. The values } \\
\text { reported here have been corrected for the presence of } 40 \% \text { slowly } \\
\text { reacting enzyme whose contribution can be neglected. Ketomalonate, } \\
\alpha \text {-ketoglutarate, and benzoylformate at concentrations of } 0.02-20 \mathrm{mM} \\
\text { keto acid, } 40-60 \mathrm{mM} \text { AIB, and } 0.02-0.1 \mu \mathrm{M} \text { DGD gave no detectable } \\
\text { transamination reaction assayed by } 2^{\circ} \mathrm{ADH} \text { coupled reaction. The } \\
\text { calculated limit on } k_{\mathrm{cat}} / K_{\mathrm{M}} \text { for these substrates is } 0.2 \mathrm{M}^{-1} \mathrm{~s}^{-1} \text {. Errors } \\
\text { are given in parentheses. }{ }^{b} k_{\max } \text { was calculated from the observed } k_{\mathrm{cat}} \\
\text { values and the value of } k_{\max } \text { for AIB given in Table } 1 \text { using } k_{\max }= \\
\left(k_{\mathrm{cat}} k_{\mathrm{AIB}}\right) /\left(k_{\mathrm{AIB}}-k_{\mathrm{cat}}\right){ }^{c} k_{\text {cat }} / K_{\mathrm{M}} \text { has been corrected by a factor of } 260 \\
\text { for hydration }(21) \text { and of } 150 \text { for the intrinsically greater reactivity of } \\
\text { aldehydes toward Schiff base formation compared to ketones }(22) \text {. }\end{array}$} \\
\hline
\end{tabular}

site. Such a model is shown in Figure 6. The A subsite is the one that maintains the scissile bond perpendicular to the plane of the pyridine ring (i.e., parallel to the $\mathrm{p}$ orbitals of the $\pi$ system), and, therefore, the site at which all bondmaking or -breaking events at $\mathrm{C}^{\alpha}$ will take place. The $\mathrm{B}$ and $\mathrm{C}$ subsites accept groups on $\mathrm{C}^{\alpha}$ that are not participating directly in the chemical events (i.e., the two methyl groups in AIB decarboxylation and the methyl and carboxylate groups in alanine transamination).

In this active site model, decarboxylation of AIB requires placement of the carboxylate in the A subsite for it to be labilized, and methyl groups in the B and C subsites (Chart 2). Transamination of $L$-alanine requires placement of the hydrogen at subsite A, the carboxylate at B, and the methyl group at $C$. Subsite A must therefore be capable of accommodating either a carboxylate or a hydrogen, subsite $\mathrm{B}$ either a methyl or a carboxylate group, and subsite $\mathrm{C}$ a methyl group. Toney et al. (5) proposed, on the basis of the active site structure of DGD, that the A and B subsites can fulfill the requirements of this model, and that, addition- 


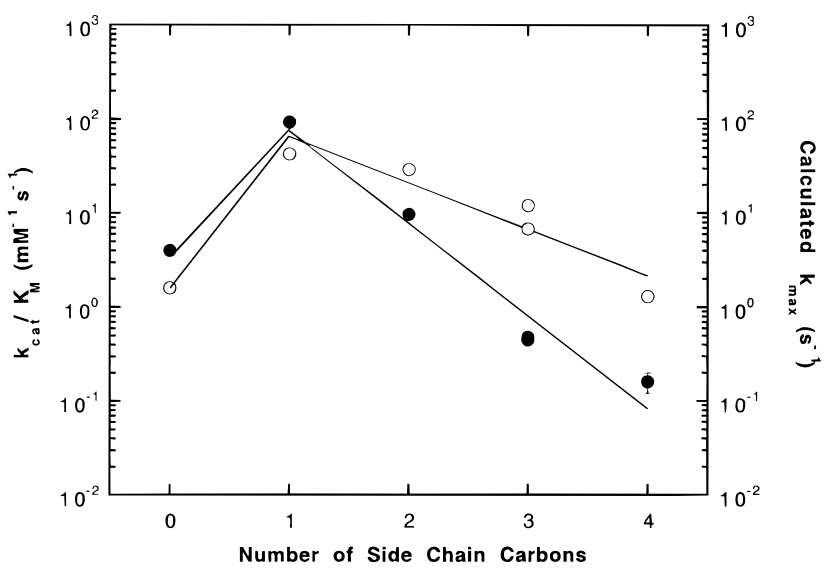

FIGURE 4: Semilog plot of rate constants for the transamination of $\alpha$-keto acids with side chains of one to four carbons in size. $\alpha$-Ketoisovalerate (three carbons) is also included. $k_{\text {cat }} / K_{\mathrm{M}}$ values (closed circles) were measured in steady-state reactions with AIB as cosubstrate. The calculated $k_{\max }$ values (open circles) for the transamination half-reactions were obtained from the observed $k_{\text {cat }}$ values, and $k_{\max }$ for the AIB decarboxylation half-reaction using $k_{\mathrm{max}}=\left(k_{\mathrm{cat}} k_{\mathrm{AIB}}\right) /\left(k_{\mathrm{AIB}}-k_{\mathrm{cat}}\right)$. The lines for zero to one carbon are drawn for the eye, while those for one to four carbons are from linear regression. Error bars are plotted over and partially obscured by the data points.

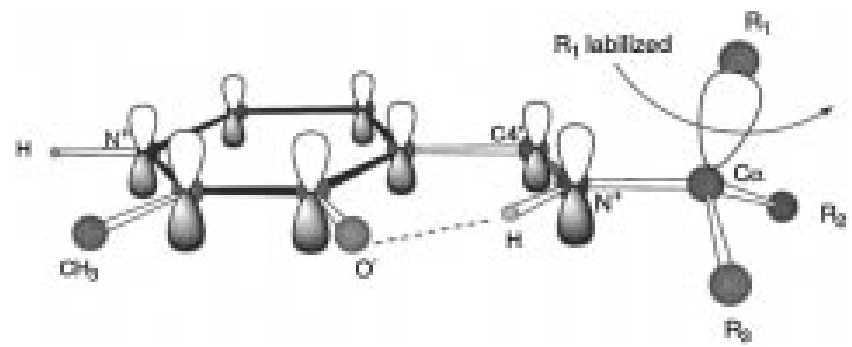

FIGURE 5: Mechanism for control of reaction specificity in PLPdependent enzymes. Dunathan (11) proposed that specific orientation about the $\mathrm{C}^{\alpha}-\mathrm{N}$ bond in the external aldimine intermediate determines which bond is labilized. The conformation in which $\mathrm{R}_{1}$ here is held perpendicular to the plane of the pyridine ring maximizes orbital overlap between the nascent carbanion and the $\pi$ system of the aldimine, thereby lowering the energy difference between ground and transition state and maximizing reaction rate.

ally, the $\mathrm{C}$ subsite is not capable of accepting a carboxylate or large alkyl group.

This model makes three testable predictions: (1) that L-alanine should undergo both transamination and decarboxylation, while D-alanine should only undergo decarboxylation since transamination requires that the $\alpha$-carboxylate group be in the $\mathrm{C}$ subsite, (2) that the active site should be capable of binding two carboxylate groups simultaneously in the A and B subsites, and (3) that increasing the size of the side chain on $\alpha$-keto acid substrates should decrease transamination reactivity since the side chain will occupy the sterically restrictive C subsite in the DGD-PMP transamination half-reaction.

These predictions are all borne out by experiment. Table 1 presents data showing that both $\mathrm{D}$ - and L-alanine are decarboxylated by DGD. The rate constants for these decarboxylation reactions are similar, and both are $\sim 500$ fold smaller than that for AIB decarboxylation. Radically different results are obtained for transamination. L-Alanine is rapidly transaminated by DGD, whereas no transamination of D-alanine is detectable (15).

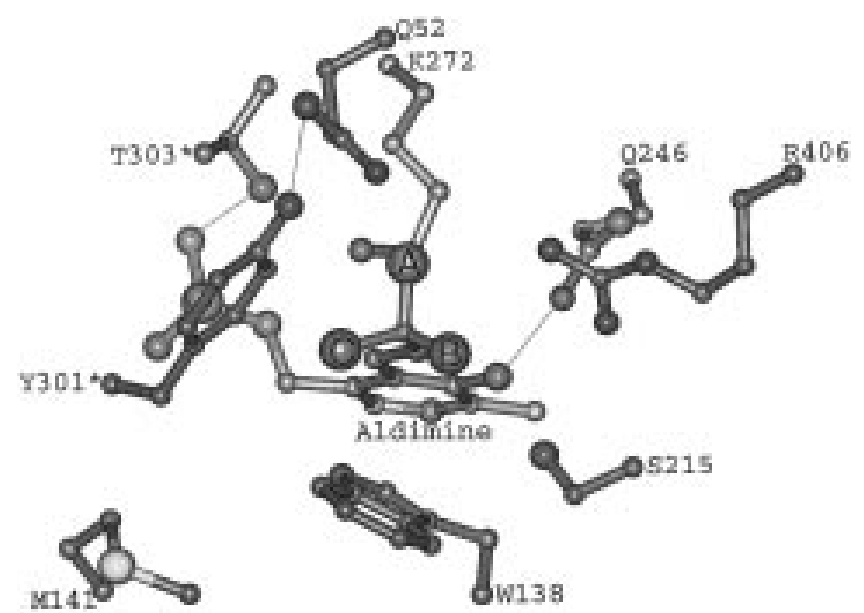

FIGURE 6: Active site model for a generic external aldimine intermediate in DGD. Thin lines denote hydrogen bonds. An asterisk marks residues donated by the opposite subunit in the dimer that forms the functional unit (5). The enlarged atoms on $\mathrm{C}^{\alpha}$ of the substrate moiety labeled A, B, and C illustrate the locations of the binding subsites discussed in the text. It is proposed that a carboxylate group at the A subsite interacts with Gln52 and possibly Lys272, while one at the B subsite interacts with Arg406 and Ser215. The C subsite cannot accept a carboxylate group. Alkyl groups at the B subsite are proposed to interact sterically with Ser215, while those at the $C$ subsite are proposed to interact with the indole ring of Trp138.

Chart 2: Conformations of Amino Acid Substrates in the DGD Active Site ${ }^{a}$

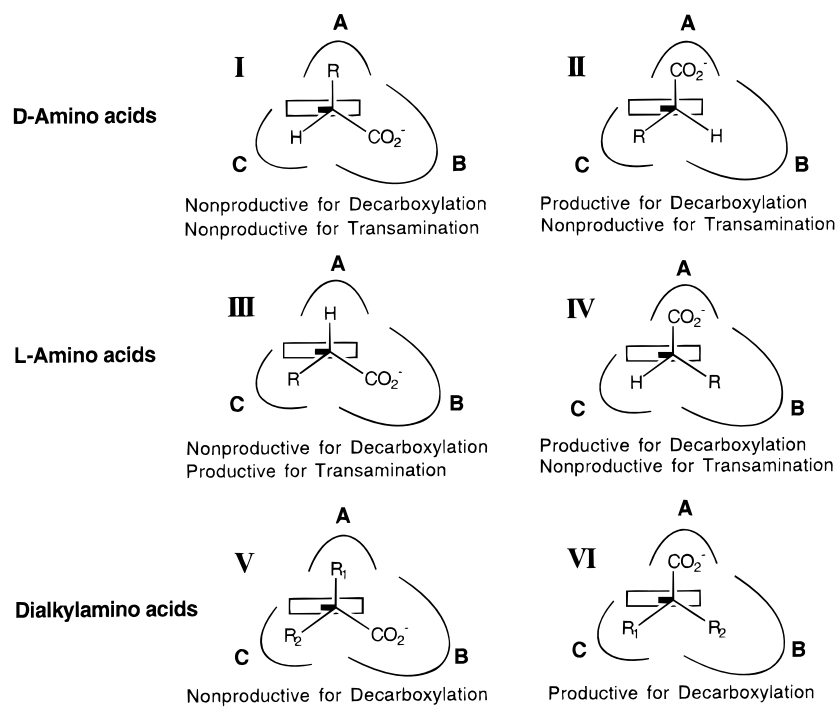

${ }^{a}$ The PLP ring is represented by the rectangle, while the aldimine bond is represented by the short, bold line. The view is directly down the $\mathrm{C}^{\alpha}-\mathrm{N}$ bond of the external aldimine. The $\mathrm{C}$ binding subsite cannot accept a carboxylate group. Thus, amino acids each have two possible conformations about the $\mathrm{C}^{\alpha}-\mathrm{N}$ bond. Bond making and breaking occurs from the A subsite only. D-Amino acids can only be decarboxylated (II) while L-amino acids can be both decarboxylated (IV) and transaminated (III). 2,2-Dialkylglycines have a productive binding mode (VI) and a nonproductive binding mode (V) for decarboxylation. The nonproductive mode $(\mathrm{V})$ represents substrate inhibition of the decarboxylation half-reaction.

The results with the aminomalonates (Table 2) clearly demonstrate that the active site is capable of productively binding two carboxylate groups simultaneously. This must occur at the A and B subsites since one carboxylate is labilized and D-alanine is not transaminated. The poor reactivity of the aminomalonates is discussed below. 
The observed linear decrease of $\log k_{\mathrm{cat}} / K_{\mathrm{M}}$ for transamination with increasing keto acid side-chain size (one to four carbons) shown in Figure 4 confirms the third prediction made from the model. The reactivities of other substrates allow one to draw an important conclusion about the relative sizes of the B vs C subsites. DGD does not decarboxylate D-phenylglycine, yet decarboxylates L-phenylglycine slightly better than L-alanine; D-phenylglycine decarboxylation requires a phenyl group in the $\mathrm{C}$ subsite, while L-phenylglycine vs L-alanine decarboxylation is equivalent to phenyl vs methyl at the B subsite. The lack of reactivity of benzoylformate (keto acid of phenylglycine) with DGD-PMP provides independent evidence that the $\mathrm{C}$ subsite will not accept a bulky phenyl group. Clearly, the active site accommodates large side chains more easily at the B than at the $\mathrm{C}$ subsite.

Ketomalonate and ketoglutarate are also unreactive in the transamination reaction with DGD-PMP. Along with the inability to transaminate D-alanine, this convincingly demonstrates that the $\mathrm{C}$ subsite is incapable of binding a carboxylate group and corroborates the conclusion that the aminomalonate carboxylate groups bind at the A and $\mathrm{B}$ subsites.

Nonproductive Binding. The proposed active site model also suggests that small amino acid substrates can be bound not only in the conformation that is productive for reaction but also in a mode that is nonproductive since there are two carboxylate binding subsites. Based on the active site structure (Figure 6), nonproductive binding appears more likely for decarboxylation than for transamination, since the interactions between a carboxylate and $\operatorname{Arg} 406 / \mathrm{Ser} 215$ at the $\mathrm{B}$ subsite are likely to be stronger than the interactions made between a carboxylate and the A subsite (i.e., Gln52 and probably Lys272). The nonproductive binding modes for AIB and L-alanine decarboxylation are illustrated in Chart 2 (III and V, respectively). The nonproductive binding mode for L-alanine decarboxylation is also the productive binding mode for L-alanine transamination since the $\mathrm{C}^{\alpha}-\mathrm{H}$ bond is positioned in the A subsite.

L-Amino Acid Reactions and Stereoelectronic Activation. The validated model of the active site in which the A subsite is the locus of bond making/breaking, the B subsite accepts carboxylate or alkyl groups rather indiscriminately, and the C subsite only accepts small alkyl groups allows one to predict the effects of varying L-amino acid side-chain size on both decarboxylation and transamination reactivities. In Figure 4, one sees for keto acid substrates with one to four side-chain carbons that, as for $k_{\text {cat }} / K_{\mathrm{M}}$, there is a linear decrease of the $\log k_{\max }$ (Table 3; calculated rate constant for the reaction of DGD-PMP with saturating keto acid) with increasing side-chain size. (The unusually low reactivity of substrates with zero side-chain carbons is discussed separately below.) This demonstrates that the effect of increasing side-chain size at the $\mathrm{C}$ subsite is not only on substrate binding but also on the reactivity of the enzyme-substrate complex since keto acids can only bind with the side chain in the $\mathrm{C}$ subsite.

L-Amino acids have conformations III and IV (Chart 2) available to them. The former is productive while the latter is nonproductive for transamination. Knowing that the $\mathrm{B}$ subsite is more sterically tolerant than the $\mathrm{C}$ subsite, one can predict that increasing side-chain size will be detrimental to the reactivity of the enzyme-substrate complex toward transamination in two ways. The first is the effect on the reactivity of the productive conformation III, while the second is the tendency of the larger side chains to drive the enzyme-substrate complex into the nonproductive conformation IV due to the larger size of the $\mathrm{B}$ vs $\mathrm{C}$ subsite. These predictions are realized in the data, as seen in Figure 3. Note the substantially larger effect of variation from one to four side-chain carbons on L-amino acid transamination compared to D-amino acid decarboxylation, as this relates to the D-amino acid discussion below.

The decarboxylation of L-amino acids occurs from conformation IV. This conformation is promoted by increasing side-chain size since the B subsite is sterically more tolerant than the $C$ subsite. Thus, increasing substrate size should increase the observed $k_{\text {cat }}$ value. This remarkable prediction is borne out by experiment as seen in Figure 2 .

The small magnitude of the increase in $k_{\text {cat }}$ as well as the decrease observed between three and four carbons suggests that although the B subsite is sterically more tolerant than the $\mathrm{C}$ subsite, increasing side-chain size at the $\mathrm{B}$ subsite also decreases the reactivity of the enzyme-substrate complex. The magnitude of the increase in $k_{\text {cat }}$ due to increasing substrate size is additionally dependent on the conformational equilibrium constant (i.e., $[\mathrm{III}] /[\mathrm{IV}]$ ) for L-alanine. For example, if the value of this constant is 1 , then only a doubling of $k_{\mathrm{cat}}$ is possible. No data are presently available that allow the determination of this equilibrium constant.

The increase in $k_{\text {cat }}$ with side-chain size demonstrates that alternative binding modes for amino acids indeed exist. This is a rare case where alternative binding modes/substrate inhibition is kinetically demonstrable. The increase also demonstrates that decarboxylation occurs preferentially from the A subsite, which orients the $\mathrm{C}^{\alpha}-\mathrm{CO}_{2}{ }^{-}$bond parallel to the $\mathrm{p}$ orbitals of the aldimine, thereby maximizing orbital overlap in the transition state. This strongly supports the proposal by Dunathan (11) that PLP-dependent enzymes can largely control reaction specificity by specific orientation about $\mathrm{C}^{\alpha}$ in the external aldimine intermediate.

D-Amino Acid Reactions. Predicting the effect of increasing substrate size on decarboxylation of D-amino acids is not straightforward due to a lack of information on the steric tolerance of the A subsite. Chart 2 illustrates the potential binding modes of D-alanine in the active site. Conformation I is nonproductive for both decarboxylation and transamination, while conformation II is productive for decarboxylation. Increasing side-chain size, in this case, will alter the relative affinities of the enzyme for conformation I vs conformation II, depending on the relative steric tolerances of the $\mathrm{A}$ and $\mathrm{C}$ subsites. For example, if subsite $\mathrm{A}$ is more sterically restrictive than is subsite $\mathrm{B}$, then increasing sidechain size will favor conformation II. This would tend to increase $k_{\text {cat }}$ by increasing the fraction of the enzyme population existing in the productive conformation II at saturation. On the other hand, the presence of larger side chains at the $\mathrm{C}$ subsite will lower both the reactivity and affinity of the enzyme for substrate (see above). The data in Figure 1 demonstrate that increasing side-chain size decreases both $k_{\text {cat }}$ and $k_{\text {cat }} / K_{\mathrm{M}}$. The larger effect on $k_{\text {cat }} / K_{\mathrm{M}}$ than on $k_{\text {cat }}$ reflects the behavior of the keto acids (Figure 4) and suggests that there are effects on both the affinity of the enzyme for substrate and the reactivity of the enzyme- 


\section{substrate complex.}

Reactions of $\alpha$-Unsubstituted Substrates. As mentioned above, substrates with zero side-chain carbons (i.e., glycine and glyoxylate) are very much less reactive than expected on the basis of the linear correlations with substrates having $1-4$ side-chain carbons. These results can be explained by a model in which the $\mathrm{C}^{\alpha}$ substituents play a direct role in maintenance of the scissile bond parallel to the aldimine $p$ orbitals. Examination of models for the external aldimines of L-alanine and L-isovaline (5) suggests that the substrate $\beta$-carbon at the $\mathrm{C}$ subsite directly interacts sterically with the indole ring of Trp140, that an alkyl group at subsite B interacts sterically with the Ser215 hydroxyl group, and that a carboxylate group at subsite B interacts with Arg406 and Ser215 (Figure 6). These interactions may prevent "wobble" of the external aldimine about the $\mathrm{C}^{\alpha}-\mathrm{N}$ bond, maximizing the average alignment of the scissile bond and the $\pi$ orbitals. In other words, the interaction of $\mathrm{p}$ orbitals depends on $\cos ^{2}$ $\theta$ (where $\theta$ is the angle between the orbitals), and if the proposed interactions minimize the average value of $\theta$ then they will accelerate the reaction.

The differences in decarboxylation reactivity between glycine and L-alanine (275-fold), and L-alanine and AIB (750-fold) are large and fairly even. In the decarboxylation of glycine, the scissile $\mathrm{C}^{\alpha}-\mathrm{CO}_{2}{ }^{-}$bond at the $\mathrm{A}$ subsite has no interactions at either the $\mathrm{B}$ or $\mathrm{C}$ subsite to restrain it. On the other hand, L-alanine has one methyl group at the $\mathrm{B}$ subsite, while AIB has two. Thus, it appears that two conformationally restraining interactions (at the $\mathrm{B}$ and $\mathrm{C}$ subsites) in the external aldimine are better than one, which is better than none. The difference between the effectiveness of a methyl group at the $\mathrm{C}$ vs the $\mathrm{B}$ subsite in increasing reactivity is estimated as a factor of 6 based on the difference in $k_{\text {cat }}$ between D- and L-alanine decarboxylation (Table 1), with the caveat that this value is influenced by the difference in the productive/nonproductive conformer equilibrium constant (e.g., I vs II, Chart 2).

Nonoxidative Decarboxylation of Amino Acids. Table 1 includes data for the percentage of nonoxidative decarboxylation observed in the reactions of several amino acids. All 2,2-dialkylamino acids tested (AIB, AC5C, AC6C) give undetectable amounts of nonoxidative decarboxylation. ${ }^{3}$ On the other hand, the monoalkylamino acids all give substantial amounts of nonoxidative decarboxylation. The ratio of nonoxidative decarboxylation for L-alanine vs AIB is $>10^{4}$; the presence of two vs one alkyl groups on $\mathrm{C}^{\alpha}$ strongly influences reaction specificity in the decarboxylation reaction. The reason for this influence of alkyl groups at the B and C subsites on reaction specificity is not evident but may be related to their strong influence on decarboxylation reactivity discussed above (i.e., steric restriction of "wobble" may also be important to preventing $\mathrm{C}^{\alpha}$ protonation).

The aminomalonates (Table 2) were synthesized to discriminate between two mechanistic alternatives for oxida-

\footnotetext{
${ }^{3}$ The unreactivity of $\mathrm{AC} 3 \mathrm{C}$ is surprising given that of $\mathrm{AC} 5 \mathrm{C}$ and AC6C. The X-ray structure of the AC3C complex (V. N. Malashkevich, M. D. Toney, P. Strop, J. N. Jansonius, unpublished results) shows an aldimine bond that is twisted fully out of the plane of the PLP ring toward the substrate binding site. This allows the cyclopropane ring to be accommodated in the active site and the carboxylate group to interact with Arg406. This unusual aldimine conformation may be the origin of the unreactivity of $\mathrm{AC} 3 \mathrm{C}$.
}

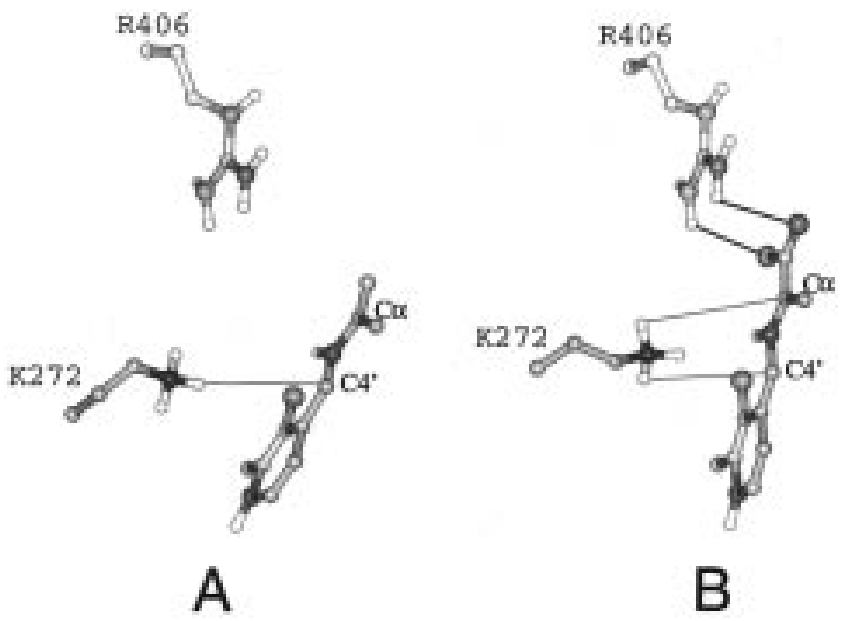

FIGURE 7: Model for the observed specificity toward $\mathrm{C}^{\alpha}$ protonation with substrate either containing or lacking a carboxylate group bound in the B subsite during the course of reaction. In this model, the quinonoid intermediate of (A) AIB tilts forward such that $\mathrm{C}^{\alpha}$ is inaccessible by Lys 272 and therefore cannot be protonated, while the quinonoid intermediate of (B) either L-alanine (from $\mathrm{C}^{\alpha}$ deprotonation) or MAM (from decarboxylation) has a carboxylate group that interacts electrostatically with Arg406, maintaining a coenzyme conformation that allows protonation of either $\mathrm{C}^{\alpha}$ or $\mathrm{C}^{\prime}$. Bold lines indicate hydrogen bond-salt bridge interactions and thin lines illustrate the proposed accessibility of either $\mathrm{C}^{\alpha}$ or $\mathrm{C}^{\prime}$ by Lys272.

tive decarboxylation specificity. The difference between oxidative and nonoxidative decarboxylation is protonation of the quinonoid intermediate (assuming it exists) on $\mathrm{C}^{\prime}{ }^{\prime}$ of the coenzyme vs $\mathrm{C}^{\alpha}$ of the substrate moiety (Scheme 2). Transamination of L-alanine/pyruvate is fully reversible. Therefore, the quinonoid intermediate in this half-reaction is readily protonated on either $\mathrm{C}^{\alpha}$ or $\mathrm{C}^{\prime}$. What differences exist between this quinonoid and that in the decarboxylation of AIB that could account for the difference in reaction pathways available to each? The only clear chemical difference is the presence of two methyl groups from AIB vs a methyl group (C subsite) and a carboxylate group (B subsite) from L-alanine/pyruvate.

Coenzyme reorientations on going from internal aldimine to external aldimine intermediates have been demonstrated for several PLP enzymes $(25-28)$ most clearly by crystallographic analyses on aspartate aminotransferase (29). In the latter case, the coenzyme rotates forward about the C5$\mathrm{C}^{\prime}$ axis by $\sim 30^{\circ}$, toward the substrate and away from the lysine that forms the internal aldimine. A similar PLP reorientation has been proposed for DGD (5). Formation of the quinonoid intermediate in aspartate aminotransferase was proposed to lead to further forward rotation of the coenzyme-substrate adduct (29).

One mechanism by which the presence of a carboxylate group at the B subsite could allow for protonation at $\mathrm{C}^{\alpha}$ is modulation of the quinonoid tilt angle by interaction with Arg406. That is, if the $\operatorname{Arg} 406-\mathrm{CO}_{2}{ }^{-}$interaction enforces a smaller tilt angle such that $\mathrm{C}^{\alpha}$ is closer to and physically accessible by Lys 272 , then protonation could occur. On the other hand, the methyl group in the B subsite of the AIB quinonoid could not interact electrostatically with Arg406, potentially allowing the tilt angle to be larger with a concomitantly greater separation between $\mathrm{C}^{\alpha}$ and Lys 272 . This is illustrated in Figure 7. 
A second explanation for oxidative decarboxylation specificity is that reaction proceeds via an asymmetric, concerted $\mathrm{C}^{\alpha}-\mathrm{CO}_{2}{ }^{-}$bond-breaking/ $\mathrm{C} 4^{\prime}-\mathrm{H}$ bond-making transition state, with $\mathrm{C}-\mathrm{C}$ bond breaking leading $\mathrm{C}-\mathrm{H}$ bond formation. This would avoid formation of the quinonoid intermediate altogether. Analogous concerted transition states have been proposed for nonenzymatic model transaminations (30) and for aspartate aminotransferase (31).

The first mechanism predicts that the aminomalonates will have a nonoxidative/oxidative decarboxylation ratio similar to the $\mathrm{C}^{\alpha} / \mathrm{C}^{\prime}$ protonation ratio observed for $\mathrm{L}$-alanine since the quinonoids formed from the aminomalonates have a carboxylate group at the B subsite to interact with Arg406. The second mechanism predicts that the aminomalonates will have a very low nonoxidative/oxidative decarboxylation ratio, assuming that the concerted mechanism would be enforced for these substrates.

A large fraction of the reactions of the aminomalonates proceed via nonoxidative decarboxylation (Table 2), even more than with the monoalkylamino acids (Table 1). This is not due to an intrinsic tendency of the aminomalonates to undergo $\mathrm{C}^{\alpha}$ protonation since both coenzyme-catalyzed decarboxylation of MAM and transamination of L-alanine in solution occur with equal protonation of $\mathrm{C}^{\alpha}$ and $\mathrm{C}^{\prime}$ (32, 33). The aminomalonate results provide strong evidence in favor of the first mechanism discussed above, namely, that the presence or absence of a carboxylate group in the B subsite of the quinonoid intermediate largely determines the ability of DGD to protonate $\mathrm{C}^{\alpha}$.

Additional support for the first mechanism comes from a comparison of the transamination reactivities of isopropylamine and L-alanine. The $10^{4}$-fold lower $k_{\text {cat }} / K_{\mathrm{M}}$ for isopropylamine (Table 1) demonstrates that the presence of a carboxylate group in the B subsite is important for proton transfer to and from $\mathrm{C}^{\alpha}$. This can be rationalized in a manner analogous to that for decarboxylation reaction specificity; i.e., the $\mathrm{Arg} 406-\mathrm{CO}_{2}{ }^{-}$interaction maintains a coenzyme tilt angle that allows Lys272 physical access to $\mathrm{C}^{\alpha}$. The $K_{\mathrm{M}}$ value for isopropylamine is only 10 times the L-alanine $K_{\mathrm{M}}$ value. Energetically this represents $1.4 \mathrm{kcal} / \mathrm{mol}$, which is much less than expected for an $\mathrm{Arg}-\mathrm{CO}_{2}{ }^{-}$interaction (20, 34). This suggests that some of the $\operatorname{Arg} 406-\mathrm{CO}_{2}{ }^{-}$interaction energy may be used, as proposed here, to increase $\mathrm{C}^{\alpha}$ reactivity in the enzyme-substrate complex by maintaining an energetically unfavorable coenzyme tilt angle that allows Lys272 access to it.

Malonic acids are intrinsically reactive toward decarboxylation, and aminomalonates are no exception (35). AIB, on the other hand, is not. One can calculate from the data of Thanassi (32) for MAM and of Kalyankar and Snell (36) for AIB that MAM is nonenzymatically decarboxylated by PLP $\sim 10^{5}$-fold faster than is AIB. Yet in the DGD active site, AIB reacts $\sim 10^{4}$-fold faster. This radical inversion of the relative reactivities of MAM and AIB on going from solution to the DGD active site suggests that AIB and MAM may not share a common rate-determining step in the DGD active site. Rapid kinetic studies of these reactions $(37,38)$ suggest that external aldimine formation with AIB is rapid while that with MAM is very much slower, although not rate determining. Thus, one might speculate that any additional steps between external aldimine formation and $\mathrm{CO}_{2}$ loss (e.g., conformational changes) are also adversely effected and may have become rate determining (38). In the absence of such a change in rate-determining step, it would be difficult to explain the enormous reactivity reversal on going from solution to the enzyme since trends in solution reactivities are generally reflected in enzymatic reactivities for a homologous set of substrates (39).

\section{ACKNOWLEDGMENT}

Critical reading of the manuscript and valuable comments provided by Professors R. L. Schowen and M. H. O'Leary are gratefully acknowledged.

\section{REFERENCES}

1. Aaslestad, H. G., and Larson, A. D. (1964) J. Bacteriol. 88, 1296-1303.

2. Bailey, G. B., and Dempsey, W. B. (1967) Biochemistry 6, 1526-1533.

3. Honma, M., and Shimomura, T. (1974) Agric. Biol. Chem. $38,953-958$

4. Toney, M. D., Hohenester, E., Cowan, S. W., and Jansonius, J. N. (1993) Science 261, 756-759.

5. Toney, M. D., Hohenester, E., Keller, J. W., and Jansonius, J. (1995) J. Mol. Biol. 245, 151-179.

6. McPhalen, C. A., Vincent, M. G., and Jansonius, J. N. (1992) J. Mol. Biol. 225, 495-517.

7. Mehta, P. K., Hale, T. I., and Christen, P. (1993) Eur. J. Biochem. 214, 549-561.

8. Mehta, P. K., and Christen, P. (1994) Biochem. Biophys. Res. Commun. 198, 138-143.

9. Jansonius J. N., Genovesio-Taverne J. C., Hennig M., Hohenester E., Jenny M., Malashkevich, V. N., Moser M., Muller R., Shen B. W., Stark W., von Stosch A., and Toney M. D. (1994) in Biochemistry of Vitamin B6 and PQQ (Marino, G., Sannia, G., and Bossa, F., Eds.) Birkhauser-Verlag, pp 2935, Basel.

10. Watanabe, N., Sakabe, K., Sakabe, N., Higashi, T., Sasaki, K., Aibara, S., Morita, Y., Yonaha, K., Toyama, S., and Fukutani, H. (1989) J. Biochem. 105, 1-3.

11. Dunathan, H. C. (1966) Proc. Natl. Acad. Sci. U.S.A. 55, 712716.

12. McPhalen, C. A., Vincent, M. G., Picot, D., Jansonius, J. N., Lesk, A. M., and Chothia, C. (1992) J. Mol. Biol. 227, 197213.

13. O'Leary, M. H., and Piazza, G. J. (1978) J. Am. Chem. Soc. $100,632-633$.

14. Milne, J. J., and Malthouse, P. G. (1996) Biochem. J. 314, 787-791.

15. Bailey, G. B., Chotamangsa, O., and Vuttivej, K. (1970) Biochemistry 9, 3243-3248.

16. Keller, J. W., Baurick, K. B., Rutt, G. C., O’Malley, M. V., Sonafrank, N. L., Reynolds, R. A., Ebbesson, L. O. E., and Vajdos, F. F. (1990) J. Biol. Chem. 265, 5531-5539.

17. Lee, K. M., Dahlhauser, K. F., and Plapp, B. V., (1988) Biochemistry 27, 3528-3532.

18. Sekhar, V. C., and Plapp, B. V. (1990) Biochemistry 29, 42894295.

19. Toney, M. D., and Kirsch, J. F. (1993) Biochemistry 32, 14711479.

20. Cronin, C. N., and Kirsch J. F. (1988) Biochemistry 27, 45724579.

21. Rendina, A. R., Hermes, J. D., and Cleland, W. W. (1984) Biochemistry 23, 5148-5156.

22. Conant, J. B., and Bartlett, P. D. (1932) J. Am. Chem. Soc. 54, 2881-2899.

23. Deslongchamps, P. (1983) in Stereoelectronic effects in organic chemistry, Pergamon, New York.

24. Benner, S. A. (1988) Stereoelectronic analysis of enzymatic reactions. In Mechanistic principles of enzyme activity (Lie- 
bman, J. F., and Greenberg, A., Eds.) Chapter 2, VCH, New York.

25. Rozenberg, M. V., Makarov, V. L., and Torchinskii, I. M. (1988) Mol. Biol. (Moscow) 22, 1132-1140.

26. Zakomyrdina, L. N., Sakharova, I. S., and Torchinskii, I. M. (1989) Mol. Biol. (Moscow) 23, 1596-1602.

27. Moore, P. S., Dominici, P., and Voltattorni, C. B. (1995) Biochimie 77, 724-728.

28. Schnackerz, K. D., Tai, C. H., Simmons, J. W., Jacobson, T. M., Rao, G. S., and Cook P. F. (1995) Biochemistry 34, 12152-12160.

29. Kirsch, J. F., Eichele, G., Ford, G. C., Vincent, M. G., Jansonius, J. N., Gehring, H., and Christen, P. (1984) J. Mol. Biol. 174, 497-525.

30. Bruice, T. C., and Topping, R. M. (1963) J. Am. Chem. Soc. $85,1488-1493$.

31. Julin, D. A., and Kirsch, J. F. (1989) Biochemistry 28, 38253833.
32. Thanassi, J. W. (1972) Biochemistry 11, 2909-2914.

33. Dixon, J. E., and Bruice, T. C. (1973) Biochemistry 12, $4762-$ 4766.

34. Hart, K. W., Clarke, A. R., Wigley, D. B., Waldman, A. D., Chia, W. N., Barstow, D. A., Atkinson, T., Jones, J. B., and Holbrook, J. J. (1987) Biochim. Biophys. Acta 914, 294-298.

35. Thanassi, J. W. (1970) Biochemistry 9, 525-532.

36. Kalyankar, G. D., and Snell, E. E. (1962) Biochemistry 1, 594600 .

37. Zhou, X., and Toney, M. D. (1997) in preparation.

38. Sun, S., Bagdassarian, C., Toney, M. D. (1997) (following paper in this issue).

39. Kirsch, J. F. (1972) in Advances in Linear Free Energy Relationships (Chapman, N. B., and Shorter, J., Eds.) Chapter 8, Plenum, New York.

BI972055S 